\title{
Protection of an HVDC Link Towards Modeling and Simulation Based DC Connection Defects
}

\author{
Mankour Mohamed ${ }^{1, *}$, Benslama Sami ${ }^{2}$ \\ ${ }^{I}$ Department of Electrotechnical and Automatic Engineering \\ University of Relizane- Ahmed Zabana; Relizane, Algeria \\ ${ }^{2}$ Computer and Information Technology Department, \\ King Abdulaziz University, Jeddah, Saudi Arabia \\ *Corresponding author.Email:med_mank@yahoo.com
}

\begin{abstract}
This paper aims to study the DC-link faults and recovery scenarios based on a 12-pulse HVDC (High Voltage Direct Current) link system. DC-link to ground fault is considered as one of the most serious fault that can occur on HVDC-link. Therefore, in order to understand the system behavior in the presence of this type of fault, two DC-fault scenarios are investigated. One scenario is at the sending end of the rectifier, and the other is at the receiving end of the inverter. The faults are applied mainly to study the dynamic performance of the recovery of HVDC-link system after faults, and to validate the proposed DC fault protection function. Influence of the Voltage Dependent Current Order Limiter (VDCOL) function is also studied. The digital real-time simulator laboratory (RT-Lab) platform HYPERSIM (OP-5600) is used in modeling and simulation of the HVDC-link system by means of Software-In-the-Loop (SIL) approach. The maintenance of the system stability is investigated to ensure a high performance recovery from the fault. Ramp-up recovery method used in the DCbus voltage restoration provided by the VDCOL-function, and the validated operation of protection function against DC faults show high performance recovery from the faults. The results carried out ensure safe and desired recovery from the DC-bus faults.
\end{abstract}

Keywords: Digital real-time simulator, HVDC system, DC faults, DC protection function, Simulation-In- theLoop (SIL).

\section{INTRODUCTION}

A High Voltage Direct Current (HVDC) device based on Line-Commutated Converter (LCC) technology has been commonly used worldwide for over 60 years. It is now a viable alternative to HVAC transmission systems [1] [2]. To ensure these devices' security and dependability, the integrity, safety, and fast recovery from unbalancing situations must be assessed [3]. HVDC device security necessitates safeguarding the rectifier, inverter stations, and DClink transmission [4] [5].

Several studies have been conducted on HVDC protection. Reference [6] describes the common types of HVDC-line protection, reference [7] discusses the advantages of the voltage derivative method, which allows an optimum response time for both close-up and distant faults travelling wave reflection method was proposed and addressed to protect HVDCsystems with extreme voltages.
In this analysis, conventional errors were simulated in digital real-time using a 12-pulse LCC-HVDC device. DRTS simulator, such as two-site DC-link faults; DC fault at the transmitting end of the rectifier and DC fault at the receiving end of the inverter. The effect of DC faults on HVDC link activity is investigated. The role of the DC fault recovery control mechanism is noted, and the effect of the DC safety feature to extinguish DC faults is addressed after it is found in the HVDC link. To check the device control and safety against power system failure policy.

OPAL-RT Technologies created an innovative RTLAB simulator, HYPERSIM OP-5600, to simulate electromagnetic (EMTP) and electromechanical transients and study the dynamic relationship between multiple control systems and security systems for HVDC connections. [8] [9] Formal paraphrase the primary goal of this simulation is to create a real-time simulation of an HVDC device 
connecting different types of HVAC networks. There are three types of real-time simulation methods: simulation in the loop (SIL), Hardware in the loop (HIL) and rapid control prototyping (RCP) [10] [16] Formal reformulation HYPERSIM has been used for modelling, simulation and study of the machine HVDC correlation as well as various DC-link error scenarios using Software-In-the-Loop (SIL) strategy [19] as a first step to understand the system's behavior under such kind of circumstances.

The remainder of this article is structured as follows. Section 2 defines the model under study, the controller, and the DC fault safety mechanism. Section 3 discusses the results that were collected. Finally, in Section 4, the conclusion is mentioned.

\section{SYSTEM UNDER STUDY}

\subsection{Real Time Platform:}

HYPERSIM OP-5600 is a real-time digital electromagnetic transient (EMTP) simulator created by Hydro-Quebec Research Institute (IREQ) [11] [15].

\subsection{LCC-HVDC link:}

The system depicted in Fig. 1 is a monopolar HVDClink system $(500 \mathrm{kV} / 2 \mathrm{kA})$ with 12 -pulse thyristor converters on both the rectifier and inverter sides in this analysis, which is focused on the first CIGRÉ HVDC benchmark system [12] [13]. As seen in Table 1 , the model was applied in the simulator, with the rectifier connected to the first $\mathrm{AC}$ system $(315 \mathrm{kV}$, $\mathrm{SCR}=5)$ and the inverter connected to the second AC system $(230 \mathrm{kV}, \mathrm{SCR}=3)$.
Table 1. HVDC BENCHMARK SYSTEM DATA

\begin{tabular}{|l|l|l|}
\hline Parameters & Rectifier & Inverter \\
\hline AC Voltage base & $315 \mathrm{kV}$ & $230 \mathrm{kV}$ \\
\hline Base MW & $100 \mathrm{MW}$ & $100 \mathrm{MW}$ \\
\hline System frequency & $60 \mathrm{~Hz}$ & $60 \mathrm{~Hz}$ \\
\hline Nominal DC voltage & $500 \mathrm{kV}$ & $500 \mathrm{kV}$ \\
\hline Nominal DC current & $2 \mathrm{kA}$ & $2 \mathrm{kA}$ \\
\hline Transformer $X_{c}$ & $0.18 \mathrm{pu}$ & $0.18 \mathrm{pu}$ \\
\hline Minimum Angle & 18 & 15 \\
\hline SCR & 5 & 3 \\
\hline
\end{tabular}

The main LCC HVDC link: AC systems, Power transformers, DC-link, AC-Filters [18], and Converters (rectifier and inverter) are more precisely defined in [5] and [19].

As seen in Figure 2, the device regulation's basic units are the firing and extinction angle limiter, synchronization of firing angles (firing angle and extinction angle), VDCOL (Voltage Dependent Current Order Limiter), and the safety mechanism against DC-faults. The tool used by the control device is to monitor both the DC-bus voltage and the DC-bus current on both sides of the DC-link. One proportional-integral (PI) controller controls the rectifier side DC-bus current, while another PI controller at the inverter side controls the DC-bus voltage. These regulators work correctly. Rec fire angles for the rectifier, as well as inv firing and extinction angles for the inverter. The DC-link voltage is governed with a slope defined by a current margin of $\mathrm{Id}=0.1 \mathrm{pu}$ and a voltage margin of $\mathrm{Vd}=0.05 \mathrm{pu}$.

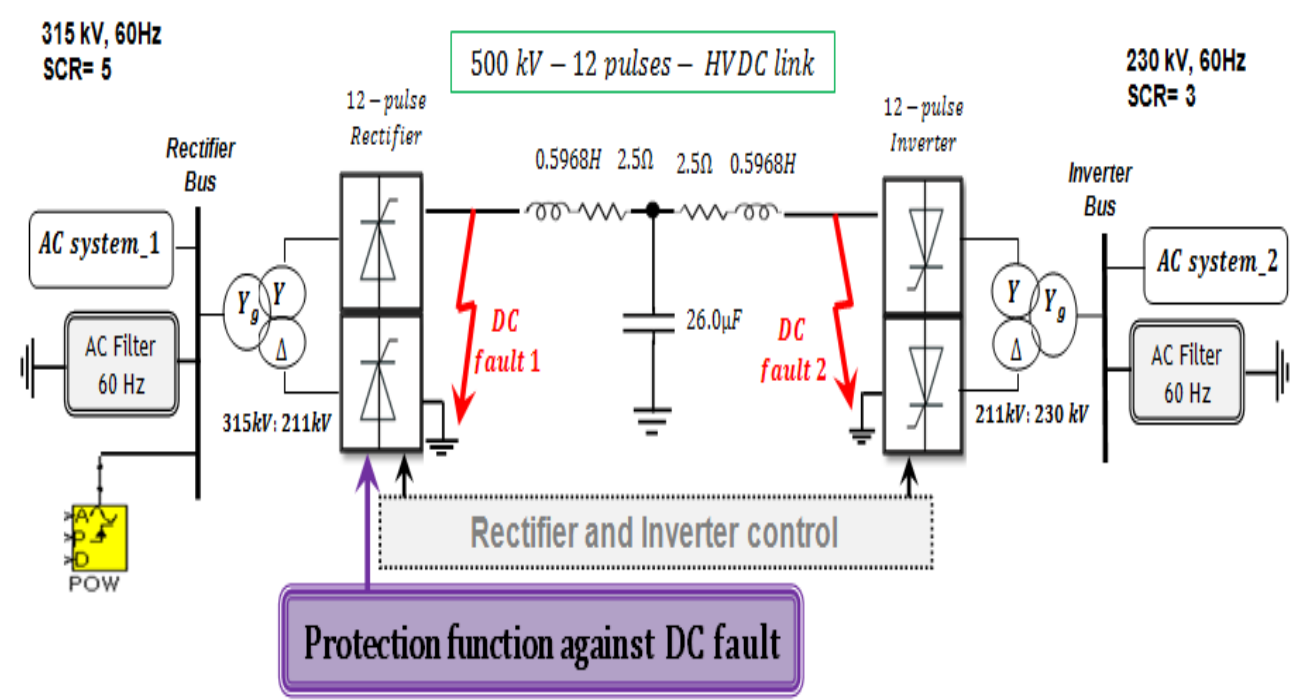


Fig. 1. Block diagram of HVDC-link system under study.

Voltage-Dependent Current Order Limiter (VDCOL) mechanism: VDCOL function generates protective DC-bus current references when accompanying DCbus decreases in the event of a fault disruption. The device controller's regulator employs the concern created by the VDCOL-function to protect the HVDC connection and its components during fault disturbances. Id ref represents the existing reference set by the VDCOL-function and is based on the HVDC-link voltage Vd line. In disorders, the voltage reference set by the VDCOL-function is defined by the $\mathrm{Vd}$ line, which changes the current to its reference Id ref. This kind of disruption put the point at the DCvoltage Vd line's corresponding value [5] [14].

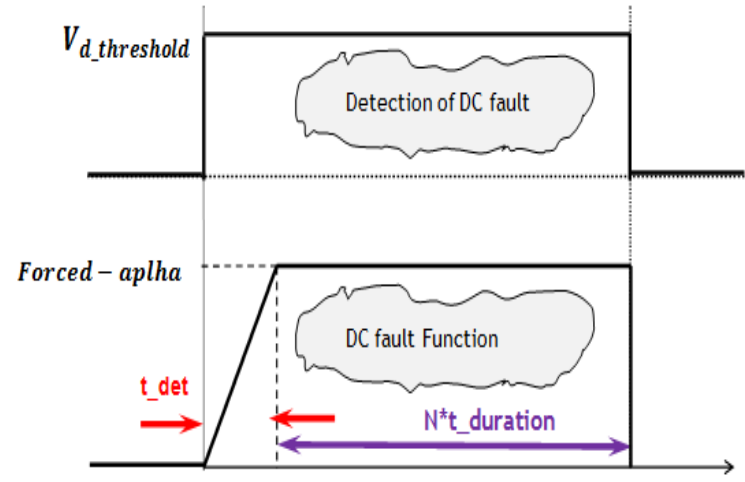

Fig. 2. Detection and reaction of the protection function.
- $t$ det: Time of detection delay of DC-fault.

- $\overline{\mathrm{V}}_{\mathrm{d} \_}$threshold: Value of DC voltage threshold used for DC-fault.

- Forced- alpha $(\alpha)$ : Value of the constant angle $\alpha$ imposed by the DC protection function after a fault is detected.

- N: Number of times the constant alpha $\alpha$ is repeated.

- t-duration: Represent the time interval which the value of the forced $\alpha$ is imposed by the DC protection.

Another advantage of this feature is that it provides a strong recovery from DC-link control transients and reduces the chance of commutation failures [17]. The following functions protect against DC faults: Direct current (DC) and alternating current (AC) faults. AC networks have normal zero crossings of currents and voltages, and they are simple to disconnect from the primary grid. As a DC fault happens in a DC-link, it is difficult to extinguish/disconnect it from the main by using a simple disconnector motion. The arc triggered by the DC-fault can be de-ionized only if the DC-fault current is decreased to zero, which is only feasible if the DC link voltage is reduced to zero using the DC-fault safety feature. The model includes a DC-protection feature for simulating DC faults and determining the efficacy of the security function.

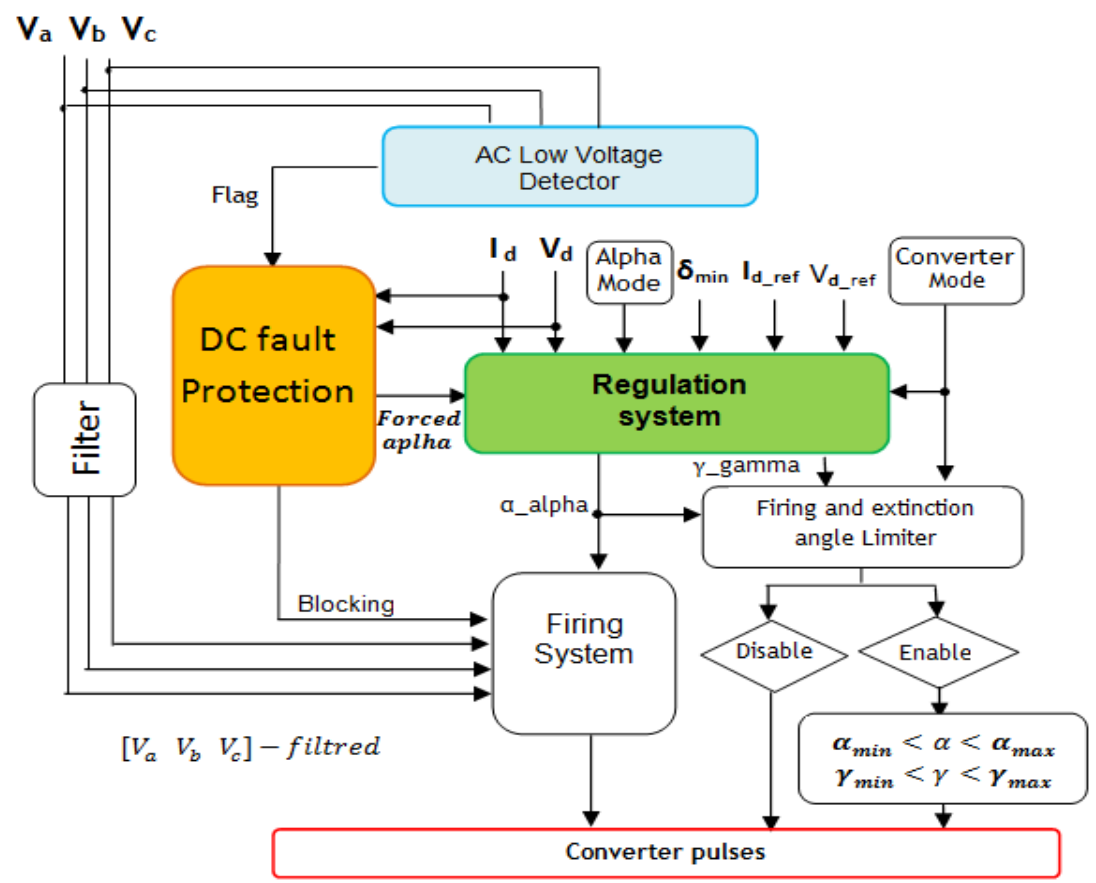

Fig. 3. The control and protection function block diagram of the HVDC-link. 
When a fault is found on the DC side, this intention takes action. Since his angle delay is provided in the term, it pushes the DC-fault current to zero as quickly as possible by supplying negative averaged DC-link voltage. As seen in Figure 2, one would be pushed to a value greater than $90^{\circ}$. As a result, no current can be used to supply the fault in this situation. The protection mechanism will be replicated before the fault is cleared (a forced angle will be applied and eventually eliminated by the protection function). After many repetitions, the security feature would disable the converter. This safety feature operation de-energizes and earns the DC-current fault very quickly.

The rectifier delay angle is less than $90^{\circ}$, while the inverter delay angle is between $90^{\circ}$ and $180^{\circ}[1][19]$. As mentioned in [3], the expression for the DC voltage at the rectifier provides the relationship between the rectifier delay angle and the DC, which is provided by the expression:

$$
V_{d-r e c}=V_{d 0-r e c} \cdot \cos (\alpha)-R_{e q-r e c} \cdot I_{d}
$$

As shown in Figure 3, the DC protection function is implemented in the control system. Its reaction is when either a DC-fault is detected on the rectifier side of the DC power system after the DC voltage falls below a defined threshold, or a low-AC-voltage is detected on the rectifier side, which is done by low-AC-voltage-detection (LACVD), which provides a low voltage flag to the DC (see Figure 2).

\section{SIMULATION RESULTS}

To put the proposed DC safety feature to the test, the DC bus fault is added to the ground fault to the rectifier transmission end first, and then to the receiving end of the inverter. In the first example, the DC protection feature is deactivated, while the operation of the HVDC-link system is checked after the DC protection function is activated.

The results are obtained with an accurate, real-time automated HYPERSIM simulator, a 50-second realtime simulation mode is selected, and all the transformer, rectifier and inverter are blocked and unblocked after the normal state is achieved.

\subsection{DC-fault at the rectifier side.}

As shown in Fig.1, a DC-link-to- ground fault error is entered at the end of the rectifier transmission. The error persists for 0.1 seconds. The DC error is entered at $\mathrm{t}=0.2 \mathrm{~s}$, as shown in Fig. 4, and the voltage on both the rectifier and inverter sides immediately drops to zero. In comparison, the current at the sending end of the rectifier rises rapidly to Irec $\mathrm{dc}=$ $5200 \mathrm{~A}$ and drops to zero at the receiving end of the inverter. In this case, the rectifier controller responds by changing the delay angle to $=89^{\circ}$ in order to keep the DC current at a minimum. A VDCOL-equipped controller will reduce the fault current to around $600 \mathrm{~A}(0.3 \mathrm{pu})$, but it cannot fully extinguish the fault current without enabling the proposed DC fault safety mechanism.

\subsection{DC-fault at the inverter side}

The DC-bus-to-ground fault is considered at the inverter's receiving end. The controller's reaction is simulated and observed using VDCOL but without the DC-fault safety feature turned on. As seen in Fig. 5 , the DC-bus fault is observed at $0.2 \mathrm{sec}$ again, and the controller with VDCOL-function is able to minimize the fault current to about $600 \mathrm{~A}(0.3 \mathrm{pu})$, but it is unable to fully clear the fault current without the proposed DC-fault safety mechanism enabled. 

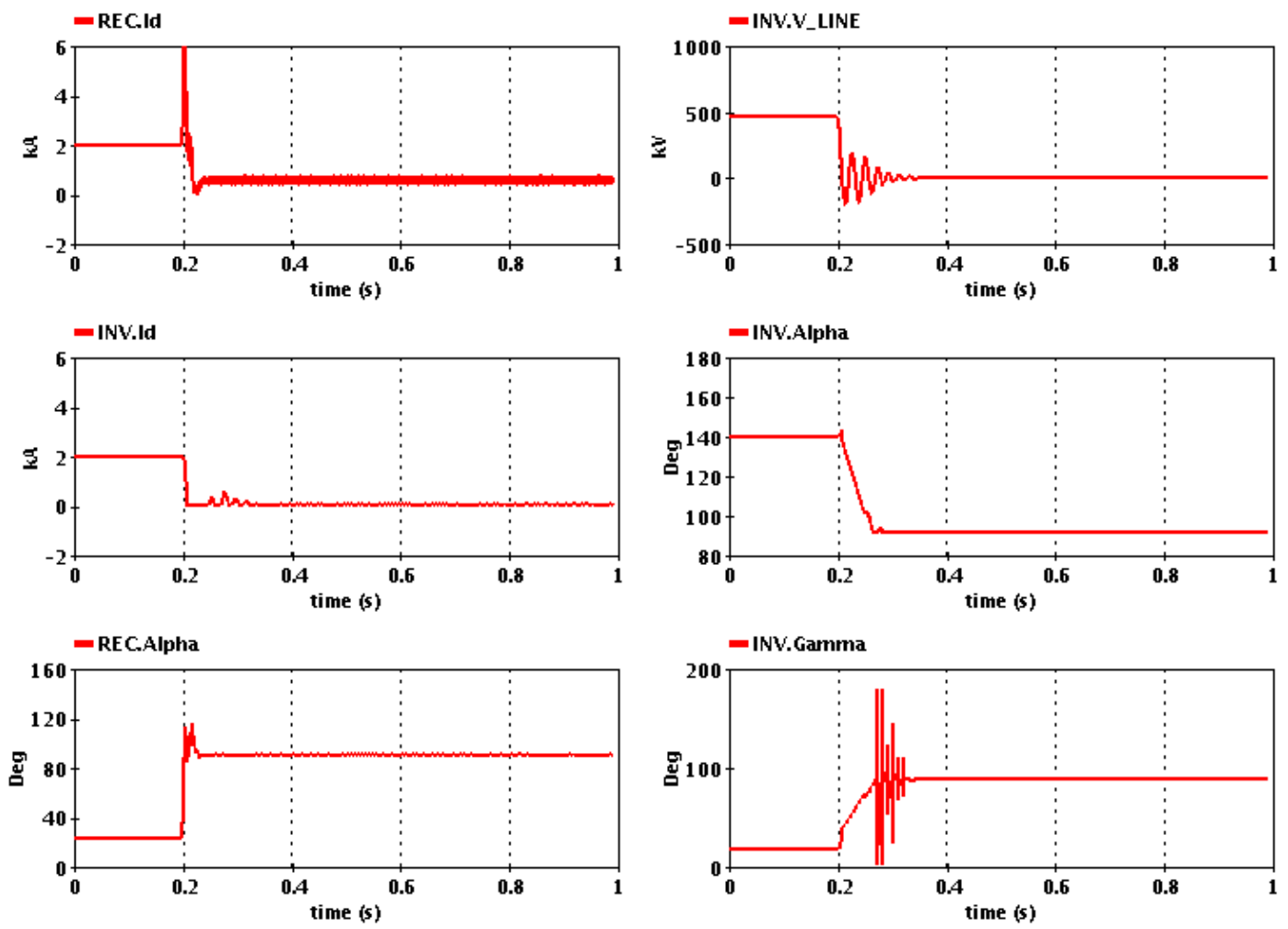

Fig. 4 Single phase to ground DC-fault at rectifier side.
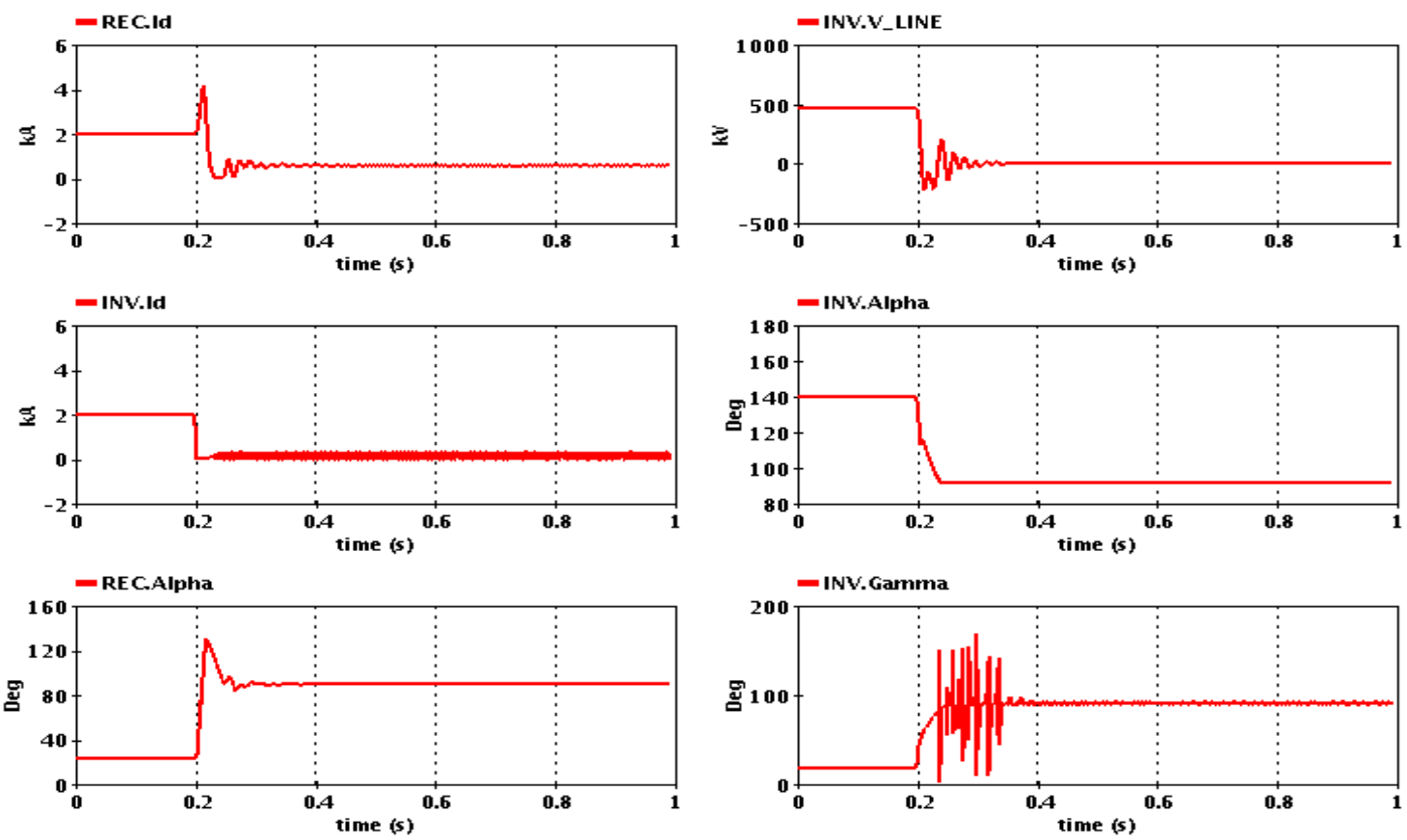

Fig. 5. Single phase-to-ground DC-fault at inverter side. 


\subsection{Validation of protection functions against DC- fault}

A DC-fault is called at the rectifier's sending end. With VDCOL and the DC-fault safety feature, the controller's response is simulated and observed this time. As seen in Figure 6, after the DC-bus fault is detected at $0.2 \mathrm{sec}$, the controller with VDCOL and DC-fault protection function will reduce the fault current to $0 \mathrm{~A}(0.0 \mathrm{pu})$, the control algorithm removes the fault completely, checks if the short-circuit is cleared, and then restores the HVDC link to its original state with a soft and smooth transition. Consequently, the simulation findings (see Figure 6) demonstrate that the proposed DC-fault safety mechanism offers high-performance fault clearance for DC-link faults and guarantees stable and rapid restoration of the HVDC-link device to its usual state.
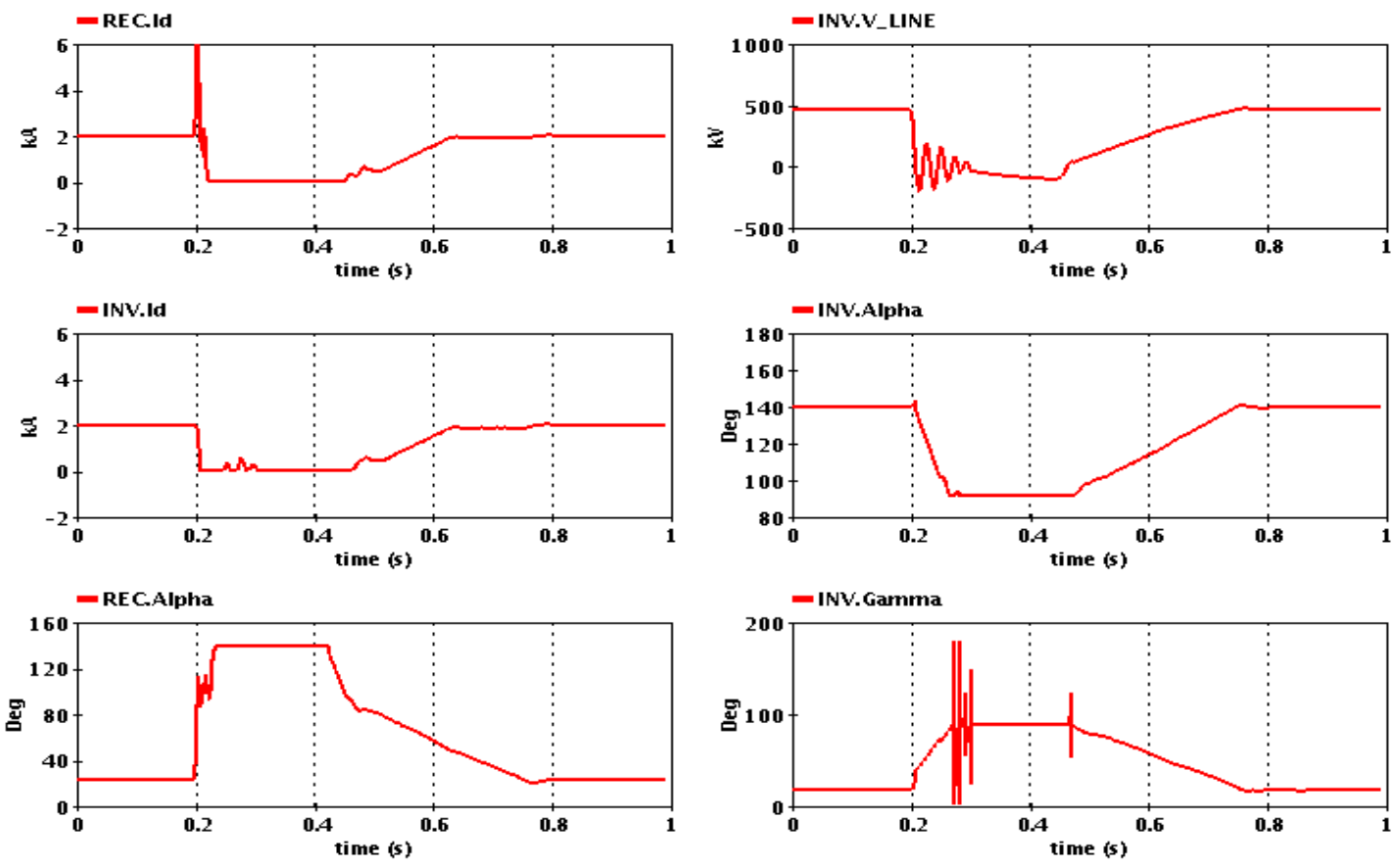

Fig. 6. Validations of the DC protection function after single phase-to-ground DC-fault at rectifier side.

When the fault occurs, the DC is rapidly bypassed until ( $\mathrm{Idc}=5200 \mathrm{~A}$ ) is detected in the rectifier side and sinks to zero at the inverter transformer. In all transformers, rectifier and inverter, the DC voltage has dropped to zero. This voltage drop is observed almost immediately by the VDCOL function, the low voltage alternating current detector (LACVD), and the DC safety function. First, VDCOL reacts by lowering the current relationship to Id ref $=600 \mathrm{~A}$ $(\mathrm{Idc}=0.3 \mathrm{pu})$, then LACVD provides a low $\mathrm{AC}$ marker for the DC protection feature, DC protection function reacts in response to science. The delay angle is pushed to $140^{\circ}$ at $\mathrm{t}=2.2 \mathrm{~s}$. The delay angle is kept at this value for some time of $t=0.2 \mathrm{~s}$ imposed by DC protection; In this phase, the DC voltage becomes negative, and the DC fault is not supplied; As a result, the power in the DC linker is returned to the $\mathrm{AC}$ system, and the $\mathrm{DC}$ fault current is de-ionized at the next zero junctions. At $\mathrm{t}=0.45 \mathrm{~s}$, the machine follows the VDCOL function's slope and returns to steady state in less than 0.4 seconds.

\section{CONCLUSION}

This study investigates the HVDC-link DC-faults by means of real-time simulations using digital real time simulator HYPERSIM OP-5600. The HVDC-link is modeled in the simulator and studied. This study proposes a simple protection function against DCfaults, which can be integrated into the main system control to eliminate the DC-faults after it is detected. Fig. 4 and 5 show that the DC-link currents after fault persist at around $600 \mathrm{~A}$, imposed by the VDCOLfunction even if the fault is detected and cleared. Therefore, it can be seen that the control system with only VDCOL functionality is not enough to 
extinguish the DC-link fault current and restore the system from the fault even if the fault is cleared. The proposed DC-fault protection scheme is not only able to detect the fault, but also to restore the DC-link to its original state after the fault is cleared within a very short time. The DC-link short-circuit current is forced to zero, does not persist and is extinguished after the fault is cleared. The proposed DC-fault protection function is shown to be very effective in restoring the HVDC-link after the faults.

\section{REFERENCES}

[1] Watson, N.R.; Watson, J.D. An Overview of HVDC Technology. Energies 2020, 13, 4342.

[2] K.R. Padiyar, HVDC Power Transmission Systems, New Academic Science Limited, second edition, 2013.

[3] Roni Irnawan, "Planning and Control of Expandable Multi-Terminal VSC-HVDC Transmission Systems" Doctoral Thesis, Springer Theses, University, Aalborg, Denmark, 2020.

[4] X. Lin, Q. Guo, H. Guo, L. Huang, Q. Chen and S. Li, "Simulation Modeling and AC System Fault Control Strategy for the Multi-terminal Hybrid HVDC System based on RTDS," 2019 IEEE Sustainable Power and Energy Conference (iSPEC), Beijing, China, 2019, pp. 337-341.

[5] Mankour, Mohamed, et al. "Modeling and real time simulation of an HVDC inverter feeding a weak AC system based on commutation failure study." ISA transactions 77 (2018): 222-230.

[6] Kai Liu, Xiaobo Yang, Youyi Li \& Jianping Wang (2018) Study of protection for serial multiterminal DC grids, Journal of International Council on Electrical Engineering, 8:1, 71-77.

[7] Muniappan, M. A comprehensive review of DC fault protection methods in HVDC transmission systems. Prot Control Mod Power Syst 6, 1 (2021).

[8] Z. Liu, Q. Wang and Y. Tang, "Design of a Cosimulation Platform With Hardware-in-theLoop for Cyber-Attacks on Cyber-Physical Power Systems," in IEEE Access, vol. 8, pp. 9599796005, 2020.

[9] P. Le-Huy, P. Giroux, J.-C. Soumagne,'RealTime Simulation of Large-Scale AC System with Offshore DC Grid" the International Conference on Power Systems Transients (ICPST-Canada), 2013.

[10] M. O. Faruque, T. Strasser, G. Lauss, V. JaliliMarandi, P. Forsyth, C. Dufour, V. Dinavahi, A. Monti, P. Kotsampopoulos,J. A. Martinez, K. Strunz, M. Saeedifard, X.Wang, D. Shearer, M. Paolone,R. Brandl, M. Matar, A. Davoudi, and R. Iravani, Real-Time Simulation Technologies for Power Systems Design, Testing, and Analysis, IEEE Power and Energy Technology Systems Journal, vol 2, no. 2, pp63-73 june 2015.

[11] X. Fan, P. Guo, F. Ma, R. Wang and G. Yang, "Real-time Simulation of Grounding Fault Protection Method Used for Medium-voltage DC Power System Based on RT-LAB," 2018 37th Chinese Control Conference (CCC), Wuhan, China, 2018, pp. 5842-5847.

[12] C. Li, Y. Zhao, F. Zeng and Z. Du, "Simulation of HVDC System Steady and Transient Response by an Analytical Method," in IEEE Access, vol. 8, pp. 142043-142054, 2020.

[13] Z. Wei, W. Fang and J. Liu, "Variable Extinction Angle Control Strategy Based on Virtual Resistance to Mitigate Commutation Failures in HVDC System," in IEEE Access, vol. 8, pp. 93692-93704, 2020.

[14] D. Kwon, Y. Kim, S. Moon,C. Kim "Modeling of HVDC System to Improve Estimation of Transient DC Current and Voltages for AC Lineto-Ground Fault-An Actual Case Study in Korea', MDPI, energies, 2017.

[15] F. Guay, P.A. Chiasson, N. Verville, S. Tremblay, P. Askvid "New Hydro-Québec Real-Time Simulation Interface for HVDC Commissioning Studies" International Conference on Power Systems Transients (IPST2017) in Seoul, Republic of Korea, June 26-29, 2017.

[16] X. Guillaud, M. O. Faruque, A. Teninge, A. H. Hariri, L. Vanfretti, M. Paolone, V.T. Dinavahi, P. Mitra, G. Lauss, C. Dufour, P. Forsyth, A. K. Srivastava, K. Strunz, T. Strasser, A. Davoudi "Applications of Real-Time Simulation Technologies in Power and Energy Systems" IEEE Power and Energy Technology Systems Journal, VOL 2, NO. 3, Sept 2015.

[17] Mankour, Mohamed, Khiat, Mounir, Ghomri, Leila, et al. Real-Time simulation of an HVDC link in dynamic state following $\mathrm{AC}$ fault. In :2018 15th International Multi-Conference on 
Systems, Signals \& Devices (SSD). IEEE, 2018. p. 911-916.

[18] J.C. DAS "Power System Harmonics And Passive Filter Designs”, IEEE Press, Wiley, 2015.
[19] Mankour, M., Sami, B.S. Mitigation of commutation failure method in LCC converter based on HVDC systems by mean of modeling and simulation. $J$ Ambient Intell Human Comput (2020). https://doi.org/10.1007/s12652020-01924-0 